\title{
Anti-CEA loaded maghemite nanoparticles as a theragnostic device for colorectal cancer
}

\author{
This article was published in the following Dove Press journal: \\ International Journal of Nanomedicine \\ 3 October 2012 \\ Number of times this article has been viewed
}

\section{Mariana Campos da Paz Maria de Fátima M Almeida Santos' \\ Camila MB Santos ${ }^{2}$ \\ Sebastião W da Silva ${ }^{2}$ \\ Lincoln Bernardo de Souza ${ }^{3}$ \\ Emília CD Lima $^{3}$ \\ Renata C Silva' \\ Carolina M Lucci' \\ Paulo César Morais ${ }^{2}$ \\ Ricardo B Azevedo' \\ Zulmira GM Lacava'}

'Instituto de Ciências Biológicas; ${ }^{2}$ Instituto de Física, Universidade de Brasília, Brasília, DF, Brazil; ${ }^{3}$ Instituto de Química, Universidade Federal de Goiás, Goiânia, GO, Brazil
Correspondence: Zulmira Guerrero Marques Lacava

Campus Darcy Ribeiro, Instituto de Ciências Biológicas, Bloco F, Térreo 70910-900, Brasília - DF, Brazil

Tel $+55613107-3087$

Fax +55 6I 3107-3087

Email zulmira@unb.br
Abstract: Nanosized maghemite particles were synthesized, precoated (with dimercaptosuccinic acid) and surface-functionalized with anticarcinoembryonic antigen (anti-CEA) and successfully used to target cell lines expressing the CEA, characteristic of colorectal cancer (CRC) cells. The as-developed nanosized material device, consisting of surface decorated maghemite nanoparticles suspended as a biocompatible magnetic fluid (MF) sample, labeled MF-anti-CEA, was characterized and tested against two cell lines: a high-CEA expressing cell line (LS174T) and a low-CEA expressing cell line (HCT116). Whereas X-ray diffraction was used to assess the average core size of the as-synthesized maghemite particles (average $8.3 \mathrm{~nm}$ in diameter), dynamic light scattering and electrophoretic mobility measurements were used to obtain the average hydrodynamic diameter $(550 \mathrm{~nm})$ and the zeta-potential $(-38 \mathrm{mV})$ of the as-prepared and maghemite-based nanosized device, respectively. Additionally, surface-enhanced Raman spectroscopy (SERS) was used to track the surface decoration of the nanosized maghemite particles from the very first precoating up to the attachment of the anti-CEA moiety. The Raman peak at $1655 \mathrm{~cm}^{-1}$, absent in the free anti-CEA spectrum, is the signature of the anti-CEA binding onto the precoated magnetic nanoparticles. Whereas MTT assay was used to confirm the low cell toxicity of the MF-anti-CEA device, ELISA and Prussian blue iron staining tests performed with both cell lines (LS174T and HCT116) confirm that the as-prepared MF-antiCEA is highly specific for CEA-expressing cells. Finally, transmission electron microscopy analyses show that the association with anti-CEA seems to increase the number of LS174T cells with internalized maghemite nanoparticles, whereas no such increase seems to occur in the HCT116 cell line. In conclusion, the MF-anti-CEA sample is a biocompatible device that can specifically target CEA, suggesting its potential use as a theragnostic tool for CEA-expressing tumors, micrometastasis, and cancer-circulating cells.

Keywords: magnetic nanoparticles, anti-CEA antibody, targeted delivery, diagnostic, Raman, biocompatible device

\section{Introduction}

Colorectal cancer (CRC) is one of the most frequently occurring cancers affecting patients worldwide. In the United States alone in 2011, there was an estimated 147,000 new cases and 50,000 deaths related to cancer of the large intestine (colon, rectum, and anus). ${ }^{1}$ Furthermore, it has been reported that 5 -year disease-free survival decreases with more advanced stages of CRC. This means that tools and methodologies that allow early cancer detection directly affect survival times and significantly reduce CRC mortality. ${ }^{2}$ 
Recently, nanostructure-based materials, such as surfacefunctionalized magnetic nanoparticles, have been tested as promising devices for early cancer detection. Additionally, magnetic nanoparticles have been used as enhanced contrast agents in magnetic resonance imaging (MRI) for noninvasive detection of cancer and lymph node metastasis ${ }^{3,4}$ with remarkable action in imaging-guided therapy. ${ }^{5}$ Maximum advantage of iron-based nanoparticles for imaging has been taken in special methods for MRI such as ultrashort echo time imaging, which improves nanoparticle contrast and enables iron quantification in tissues. ${ }^{6}$

Magnetic nanoparticles have also been investigated for cancer therapy application, as they are suitable for magnetic hyperthermia. ${ }^{78}$ Magnetic nanoparticles may also be designed for multiple potential therapeutic approaches as chemotherapeutics delivery carriers and photodynamic therapy. ${ }^{9,10}$

Both diagnostics and therapeutics can be simultaneously provided by magnetic nanoparticles, and they are therefore considered as a platform of promising theragnostic precursors, especially because magnetic targeting of the tumor may be achieved, leading to an accumulation up to eightfold higher. ${ }^{5}$ Furthermore, iron-based nanoparticles can be chemically modified with a targeting particular moiety, such as antibodies, specifically to detect tumors ${ }^{11,12}$ and circulating tumor cells, ${ }^{13}$ improving micrometastasis diagnosis. Monitoring micrometastasis appearance by detection of biological markers may be helpful in the clinical management of patients and in a specific therapy design device. In CRC patients, detection of circulating tumor cells expressing carcinoembryonic antigen (CEA) has been related to stabilization of the disease and overall survival. ${ }^{14}$

CEA is a $180-200 \mathrm{kDa}$ glycoprotein member of the immunoglobulin supergene family, whose expression is limited in normal adult tissue whereas it is widely detected in many types of primary and metastatic tumors, especially CRC. ${ }^{15,16}$ Therefore, CEA has been chosen as the targeted antigen for detection of primary and metastatic $\mathrm{CRC}^{17,18}$ and also as a possible target for antibody-mediated therapy. ${ }^{19,20}$

The aim of the present study was to develop a biocompatible magnetic fluid containing stably suspended maghemite nanoparticles (MNPs) conjugated to anti-CEA as a device for potential theragnostic approaches to CRC. The surface-enhanced Raman spectroscopy (SERS) method was innovatively used to probe the nanosized maghemite/ anti-CEA conjugation. Additionally, the right conjugation of anti-CEA to MNPs is critical for the end material device to function, and was indeed confirmed by biological tests.

\section{Material and methods \\ Preparation and characterization of the magnetic fluid (MF) sample}

Magnetite nanoparticles were synthesized by chemical coprecipitation of $\mathrm{Fe}$ (II) and $\mathrm{Fe}$ (III) ions in aqueous solution after controlled addition of the alkaline aqueous solution. Following the coprecipitation step, the as-produced nanosized magnetite sample was oxidized into MNPs using oxygen bubbling at $95^{\circ} \mathrm{C}$ for 5 hours. The MNPs were then washed with $1.5 \mathrm{~mol} / \mathrm{L} \mathrm{HCl}$ aqueous solution and separated from the supernatant using a permanent magnet. The sediment, containing the MNPs, was dispersed in $\mathrm{NaCl}$ solution and then coated with meso-2,3-dimercaptosuccinic acid (DMSA), according to the procedure previously reported for the production of stable magnetic fluid samples. ${ }^{21}$ The total iron concentration in the MF sample as determined by atomic absorption was $17 \mathrm{mg} / \mathrm{mL}$ and the crystalline mean diameter estimated from the X-ray diffractogram (X-ray diffractometer, Shimadzu XRD 6000; Shimadzu Corporation, Kyoto, Japan) using Scherrer's equation was $8.3 \mathrm{~nm}$. From these data, the concentration of nanoparticles was estimated within the as-prepared MF sample $\left(1.5 \times 10^{19}\right.$ nanoparticles $/ \mathrm{mL}$ ). The average values of the hydrodynamic diameter and zeta potential of the DMSA-coated MNPs dispersed within the MF sample were $190 \mathrm{~nm}$ and $-47.5 \mathrm{mV}$, respectively (ZetaSizer Nano S; Malvern Instruments Ltd, Malvern, UK).

\section{Cell culture}

Two human CRC cell lines were utilized in this study. The LS174T cell line was provided by Dr Fernando Kreutz (FKBiotec, Rio Grande do Sul, Brazil) and the HCT116 cell line was provided by Dr Jose Morgado Díaz (INCA, Rio de Janeiro, Brazil). Both LS174T and HCT116 cells were cultured in flasks (TPP, Trasadingen, Switzerland) with RPMI-1640 medium (Sigma-Aldrich, St Louis, MO) containing $1 \%(\mathrm{v} / \mathrm{v})$ penicillin-streptomycin (Sigma-Aldrich) and $10 \%(\mathrm{v} / \mathrm{v})$ heat-inactivated fetal bovine serum (Gibco, Carlsbad, CA). Cells were maintained at $37^{\circ} \mathrm{C}$ in humidified atmosphere with $5 \% \mathrm{CO}_{2}$.

\section{Cell viability}

In order to evaluate the MF toxicity, the MTT assay (Invitrogen, Carlsbad, CA) was performed according to Carneiro et al. ${ }^{9}$ LS174T and HCT116 cells were seeded into 96-well culture microplates at a density of $2 \times 10^{4}$ cells $/$ well for viability tests after 5 and 12 hours or $10^{4}$ cells/well for viability tests after 24 and 48 hours. The day after, cells 
were incubated with $150 \mu \mathrm{L}$ of culture medium and $50 \mu \mathrm{L}$ of phosphate-buffered saline (PBS) containing MF at eight different iron concentrations of 0.0 (negative control), $0.1,1$, $5,10,30,60,80$, and $100 \mathrm{ng} / \mu \mathrm{L}$ culture media for $5,12,24$, or 48 hours. For positive control, cells were incubated with hydrogen peroxide at 0.1 and $0.5 \mathrm{mM}$ for the same period. After treatment, cells were incubated with MTT $(5 \mathrm{mg} / \mathrm{mL})$. Cell viability was assessed by measuring the absorbance at $595 \mathrm{~nm}$, using a microplate reader (SpectraMax M2; Molecular Devices, Sunnyvale, CA).

\section{Anti-CEA conjugation to MNPs}

For conjugation of anti-CEA antibody onto MNPs EDC (1-ethyl-3-[3-dimethylaminopropyl] carbodiimide hydrochloride; Sigma-Aldrich) was used to activate terminal carboxyl groups in the DMSA-functionalized MNPs for the conjugation with primary amines of anti-human CEA antibodies. Addition of NHS (N-hydroxysuccinimide; SigmaAldrich) was used as a strategy to increase the efficiency of EDC-mediated coupling reactions by stabilization of the amine-reactive intermediate. The EDC/NHS protocol was employed as described by Acharya et al, ${ }^{22}$ with slight modifications. Briefly, $1.5 \mathrm{~mL}$ of EDC ( $1 \mathrm{mg} / \mathrm{mL}$ in PBS $)$ and $1.5 \mathrm{~mL}$ of NHS ( $1 \mathrm{mg} / \mathrm{mL}$ in PBS) were added to $30 \mathrm{~mL}$ PBS containing $1.5 \mathrm{~mL}$ MF sample (approximately $60 \mathrm{mg}$ MNPs) and left at room temperature under shaking for 4 hours. Unreacted EDC and NHS were removed by three rounds of centrifugation at 20,000 rpm for 40 minutes, at room temperature (model CR22G/CR21G; Hitachi Ltd, Tokyo, Japan). The resultant pellet was dispersed in $2 \mathrm{~mL}$ PBS and a $500-\mu \mathrm{L}$ aliquot was saved for tests and labeled MF-NHS. To the remaining MF sample (MF-NHS), anti-CEA antibody (rabbit polyclonal - DBS) was added at $200 \mu \mathrm{g} / \mathrm{mL}$ final concentration. The suspension was again left under shaking for 2 hours at room temperature and then incubated overnight at $4^{\circ} \mathrm{C}$. The unbound antibody was removed by three rounds of centrifugation at $20,000 \mathrm{rpm}$ for 40 minutes, at $4^{\circ} \mathrm{C}$, while the supernatants were saved for tests. The MNP conjugated to anti-CEA was dispersed in $1 \mathrm{~mL}$ PBS and the resulting MF sample was labeled MF-anti-CEA.

\section{Iron concentration of MF-anti-CEA}

The MF-anti-CEA iron concentration was determined by the colorimetric ferrozine method. Briefly, $100 \mu \mathrm{L} \mathrm{HCl} 1.2 \mathrm{~N}$ was added to $100 \mu \mathrm{L}$ diluted MF-anti-CEA (1:1000) and the suspension was incubated at $80^{\circ} \mathrm{C}$ for 1 hour. After cooling the suspension down to room temperature, $500 \mu \mathrm{L}$ of $15 \%$ ammonium acetate was added, followed by the addition of
$100 \mu \mathrm{L} 4 \%$ ascorbic acid, $2.5 \%$ sodium dodecyl sulfate, and 1:10 diluted ferrozine (Labtest Diagnóstica SA, Lagoa Santa, Brazil). The sample was incubated at $37^{\circ} \mathrm{C}$ for 10 minutes and the absorbance was read at $560 \mathrm{~nm}$. The MF-anti-CEA iron concentration was calculated by comparing this absorbance to the MF sample calibration curve, in which the iron concentration ran from 0.038 to $39.2 \mu \mathrm{g} / \mathrm{mL}$. The calibration curve was equally assessed by the ferrozine method.

\section{Characterization of MF-anti-CEA}

Diluted MF-anti-CEA (1:800) was dropped onto a formvar-coated grid and examined using a JEOL 1011 transmission electron microscope (JEOL, Tokyo, Japan). The hydrodynamic diameter of anti-CEA-MNPs and the zeta potential of the MF samples were determined by laser light scattering using a particle size analyzer (ZetaSizer; Malvern Instruments). The MF samples containing MNPs or anti-CEA-MNPs were analyzed in a $1 \mathrm{~cm}$ quartz cell. Measurement was performed in triplicate. All experiments were carried out at $25^{\circ} \mathrm{C}$ in the range of $100-2000 \mathrm{~Hz}$.

\section{SERS}

Anti-CEA conjugation onto the surface of the MNPs was assessed by SERS. Silver films used as substrate for SERS measurements were prepared by the electrolytic method, using a solution of $\mathrm{AgNO}_{3}(0.1 \mathrm{mg} / \mathrm{mL})$ as electrolyte. For SERS studies a solution of $10 \mu \mathrm{L} \mathrm{MF,} \mathrm{MF-NHS,} \mathrm{and} \mathrm{MF-}$ anti-CEA samples were diluted in $10 \mu \mathrm{L}$ distilled water and dripped onto the silver film, then dried with dry nitrogen. SERS spectra were immediately recorded.

The samples were excited by the $514.5 \mathrm{~nm}$ line of an Argon ion laser. A cylindrical lens was used to focus the laser beam onto the probed surface containing the samples, at a power of $0.1 \mathrm{~W} / \mathrm{cm}^{2}$. The scattered light was collected in almost backscattering configuration and analyzed using a triple spectrometer (Jobin Yvon Model T64000; Horiba, Tokyo, Japan) equipped with a charge-coupled device detector.

\section{In vitro cell binding and specificity}

In order to evaluate if the suspended nanoparticles within the MF-anti-CEA sample were capable of specifically binding to their target (CEA), LS174T (high level of CEA expression) ${ }^{23}$ and HCT116 (low level of CEA expression) ${ }^{24}$ cells were assessed by enzyme-linked immunosorbent assay (ELISA). Cells were seeded into 96-well culture microplates $\left(2 \times 10^{4}\right.$ cells/well $)$ and incubated for 24 hours to allow cell adhesion. Then cells were fixed for 10 minutes with $4 \%$ 
paraformaldehyde in PBS, washed three times with PBS, and then blocked overnight with 5\% dried milk powder in PBS. The day after, MF-anti-CEA was used as the primary antibody for 2 hours. Unbounded anti-CEA-MNPs were washed away with PBST (PBS containing 0.05\% Tween-20) and cells were incubated with alkaline phosphatase-conjugated mouse-antirabbit IgG secondary antibody (Sigma-Aldrich) for 1 hour. After two washes with PBST and one wash with APB (100 mM tris $\mathrm{HCl} \mathrm{pH} 9.5,100 \mathrm{mM} \mathrm{NaCl}, 50 \mathrm{~m} \mathrm{M} \mathrm{MgCl}{ }_{2}$ ), $200 \mu \mathrm{L}$ of pNPP (para-nitro-phenyl-phosphate) $-1 \mathrm{mg} / \mathrm{mL}$ in APB - were added. After 30 minutes, absorbance was measured at a $405 \mathrm{~nm}$ wavelength. As experimental control, the MF sample and supernatants saved from antibody conjugation were also analyzed.

\section{Perls Prussian blue iron staining}

In order to confirm anti-CEA-MNP specificity, $10^{5}$ cells were seeded on glass coverslips placed in a 24-well culture microplate and incubated for 24 hours. Either MF or MF-antiCEA samples were added to cell culture at $30 \mathrm{ng} / \mu \mathrm{L}$ final iron concentration in culture medium. After 5 hours, the cells were visualized by Prussian blue staining for iron detection. Cells were fixed for 5 minutes in ice-cold methanol, stained for 15 minutes with an equal volume of $2 \%$ hydrochloric acid and $2 \%$ potassium ferrocyanide trihydrate, and counterstained for 3 minutes with $0.5 \%$ nuclear fast red. Cells were washed with distilled water and air-dried, and coverslips were mounted in Kisser's glycerol jelly (equal volume of glycerol and $2.5 \%$ gelatin in distilled water).

\section{Transmission electron microscopy (TEM)}

Routine TEM analyses were carried out to evaluate MNP uptake by LS174T and HCT116 cells incubated for 5 hours with both MF and MF-anti-CEA samples at a final iron concentration of $60 \mathrm{ng} / \mu \mathrm{L}$. Briefly, cultured cells were centrifuged (1000 g, 2 minutes) after trypsin digestion in culture plates. The cell masses were fixed in modified Karnovsky's fixative (2\% paraformaldehyde, $2.5 \%$ glutaraldehyde in 0.1 M sodium cacodylate buffer, $\mathrm{pH} 7.2$ ) for 2 hours at room temperature. Samples were post-fixed in a solution containing $1 \%$ osmium tetroxide, $0.8 \%$ potassium ferricyanide, and $5 \mathrm{mM}$ calcium chloride and contrasted in bloc with uranyl acetate. Samples were then dehydrated in acetone and embedded in Spurr. Semi-thin sections (3 $\mu \mathrm{m})$ were stained with toluidine blue and examined under a light microscope to localize cells with visible nucleus. Ultra-thin sections $(70 \mathrm{~nm})$ were examined using a JEOL 1011 transmission electron microscope (JEOL). For all treatments, at least 50 cells in the same grid area were counted and quantified for the presence of nanoparticles inside or outside cells.

\section{Statistical analysis}

GraphPad Prism 5.0 (Sigma Stat; Prism 5.0; GraphPad Software Inc, San Diego, CA) was utilized to perform the two-way analysis of variance (ANOVA) test. When statistically significant differences were found (significance level adopted was 5\%), analysis was complemented by the Bonferroni method. Data were presented as means \pm standard error.

\section{Results MF toxicity}

As a mandatory step in the development of the potential cancer theragnostics MF-anti-CEA device, its precursor, the MF sample (DMSA-coated MNPs) was investigated in order to assess its biocompatibility. The MF sample's cytotoxicity was assessed by the MTT assay (Figure 1), using the two colon cancer cell lines (HCT116 and LS174T cells).

The results show that the MF sample induced a decrease in HCT116 cell viability (Figure 1A) when cultivated for 5 hours at iron concentrations of 60 and $80 \mathrm{ng} / \mu \mathrm{L}$. A decrease in cellular viability was also observed after 12 and 24 hours, but only at the highest iron concentration $(80 \mathrm{ng} / \mu \mathrm{L})$. However, after 48 hours, cell viability in all groups was statistically equal to the negative control (Figure 1A).

An MTT assay was also performed for LS174T cells (Figure 1B). No decrease in cell viability was observed in LS174T cells cultivated with the MF sample until 24 hours. Nevertheless, a decrease in LS174T cell viability was observed after 48 hours culture with the MF sample at iron concentration ranging from 30 to $80 \mathrm{ng} / \mu \mathrm{L}$.

\section{Synthesis and characterization of MF anti-CEA}

In order to develop a magnetic material device for therapeutic and diagnostic applications in CRC, anti-CEA antibody was bound to surface-functionalized MNPs dispersed in the MF sample using the EDC/NHS method. The resulting MF sample containing anti-CEA-MNPs was labeled MF-anti-CEA. The iron concentration of the as-prepared MF-anti-CEA was determined as $9.2 \mathrm{mg} / \mathrm{mL}$ using the ferrozine colorimetric method, while comparing its absorbance against a standard curve obtained for the MF sample $\left(\mathrm{R}^{2}=0.9975\right)$.

TEM micrographs showed that MNPs in the MF sample (Figure 2A) as well as the MNPs in the MF-anti-CEA 
A

HCT116
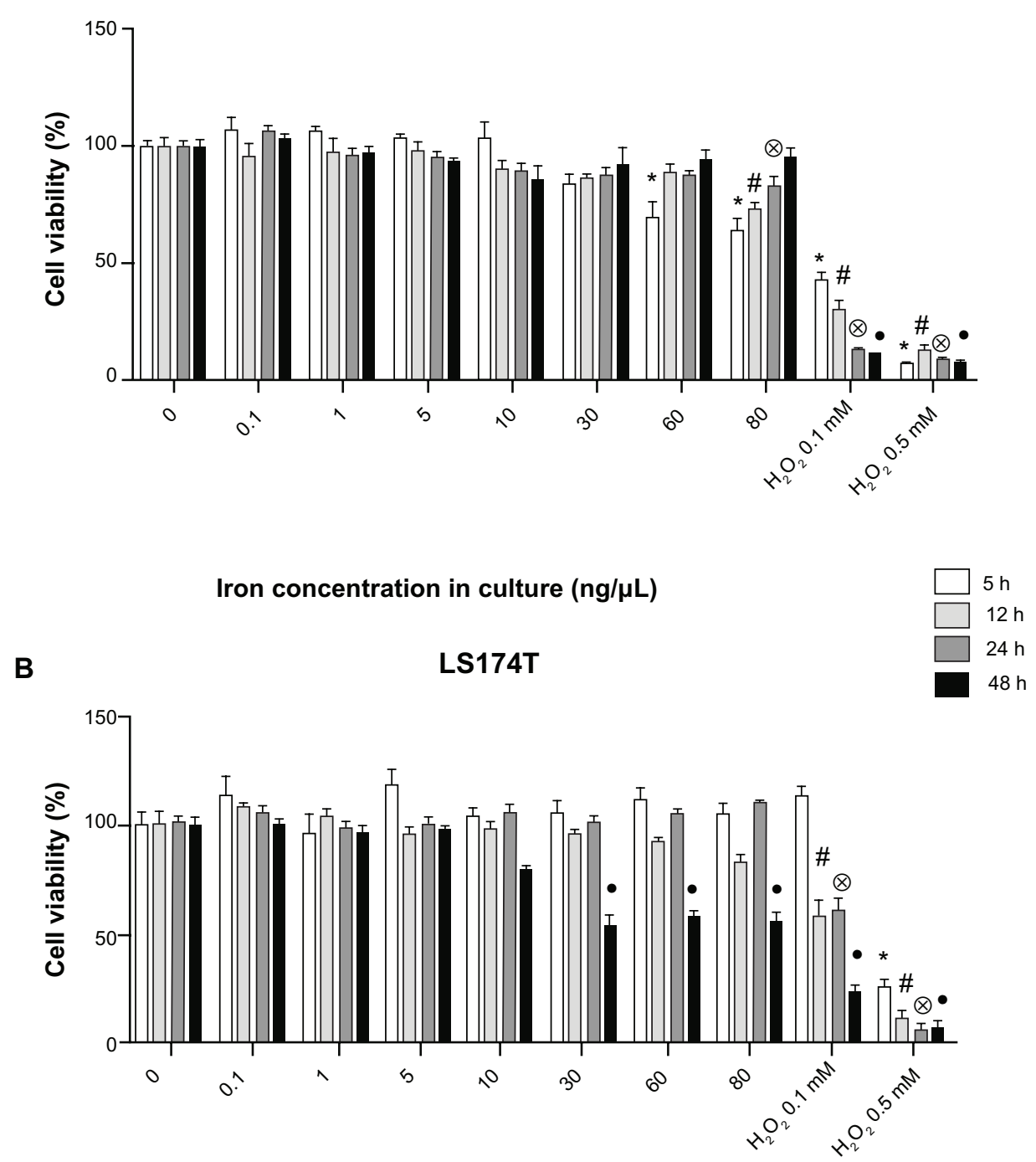

Iron concentration in culture $(\mathrm{ng} / \mathrm{\mu L})$

Figure I Evaluation of MF biocompatibility in human colorectal cancer cells. MTT assay in HCTII6 (A) and LSI74T (B) cells cultivated with MF at different iron concentrations.

Notes: Data were normalized with the negative control (cells without treatment) and expressed as mean \pm standard error of experiments performed in triplicate. Different symbols indicate statistical difference $(P<0.05)$ compared to the negative control in time 5 hours $(*), 12$ hours $(\#)$, 24 hours $(\otimes)$, and 48 hours $(\bullet)$. Cells cultivated with $\mathrm{H}_{2} \mathrm{O}_{2}$ (hydrogen peroxide at 0.1 and $0.5 \mathrm{mM}$ ) are positive control groups.

Abbreviation: MF, magnetic fluid.

sample (Figure 2B) present a spherical shape, evidencing that the antibody conjugation did not alter the MNPs' morphology. Different sized nanoparticles were also observed in the samples analyzed by TEM. Nevertheless, the polydispersity index of MNPs in the MF samples, as determined by dynamic light scattering, was 0.15 . The average hydrodynamic diameter of the MNPs suspended within the MF sample was $190 \mathrm{~nm}$ (Figure 2C). However, after antibody conjugation, the average hydrodynamic diameter of the suspended MNPs increased to approximately $550 \mathrm{~nm}$
(Figure 2D). Small peaks around $100 \mathrm{~nm}$ and $5 \mu \mathrm{m}$ are also showed in Figure 2D.

Zeta potential shifts from $-47.5 \mathrm{mV}$ (MF sample) to $-38 \mathrm{mV}$ (MF-anti-CEA sample), revealing that MNPs in both MF samples are negatively charged.

\section{SERS}

In this study SERS was used as the spectroscopy tool to evaluate the efficacy of anti-CEA antibody binding onto MNPs. Figure 3(A), (B), and (C) show the recorded SERS 

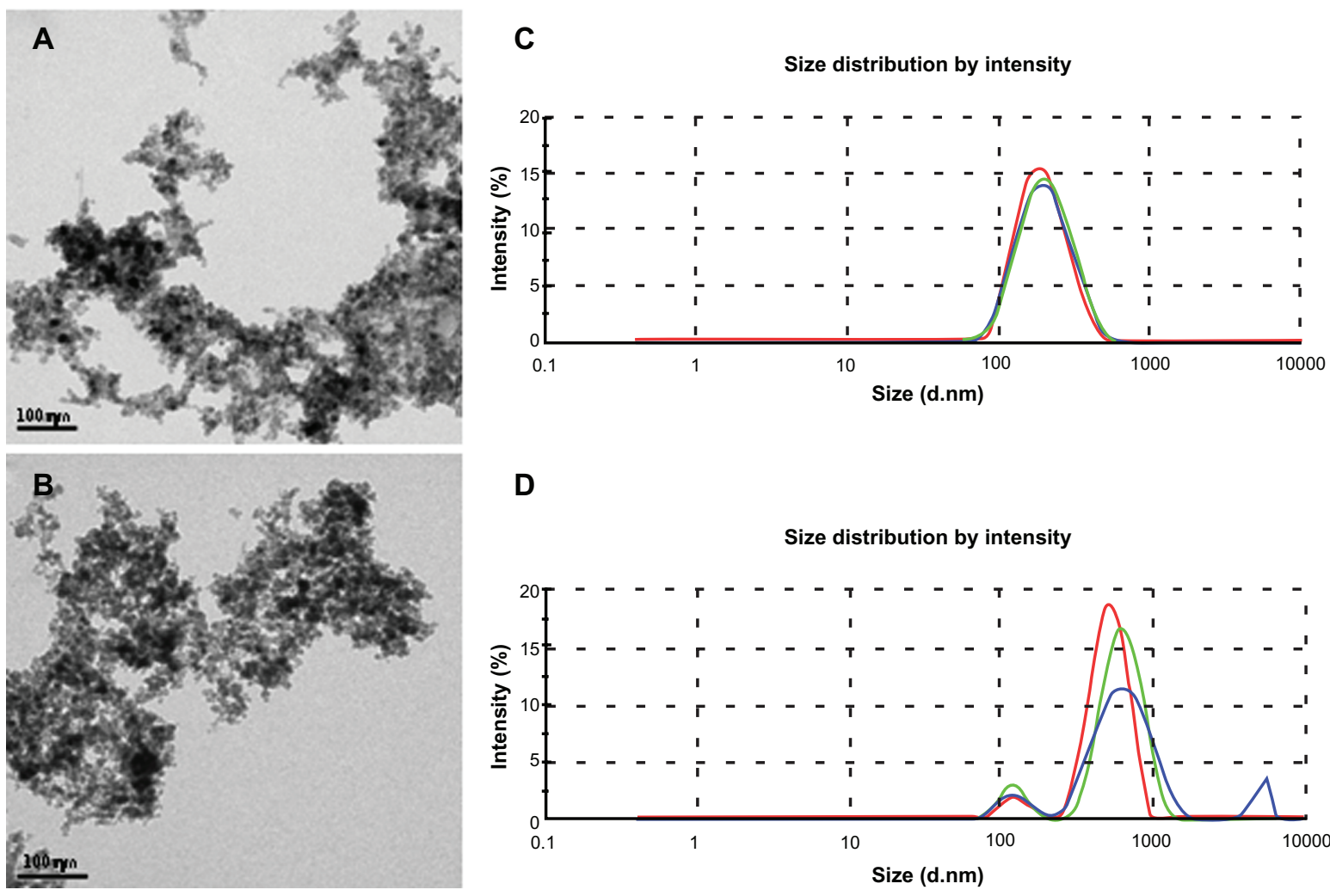

D

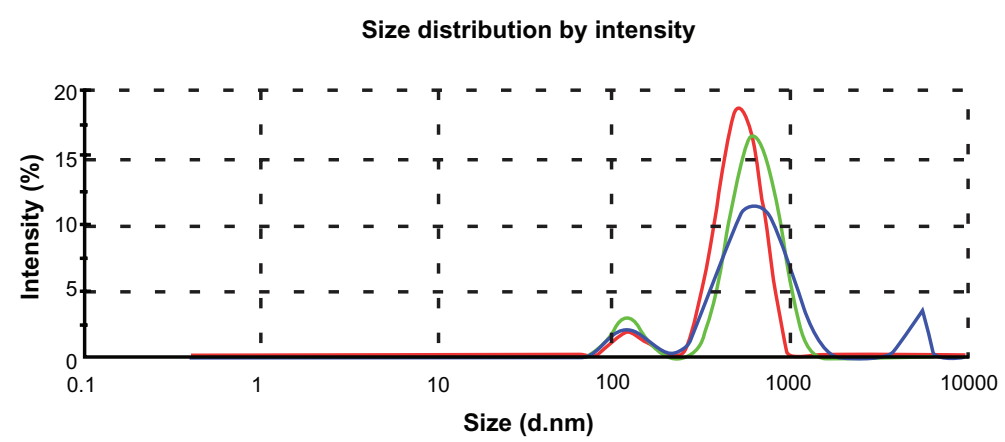

Figure 2 Characterization of nanoparticles by transmission electron microscopy and dynamic light scattering. Electron micrograph of maghemite nanoparticles in MF sample (A) and anti-CEA conjugated nanoparticles in MF-anti-CEA sample (B). Hydrodynamic size of nanoparticles in MF sample (C) and MF-anti-CEA sample (D).

Note: Red, green, and blue lines represent the first, the second, and the third measurement of the triplicate, respectively.

Abbreviations: MF, magnetic fluid; CEA, carcinoembryonic antigen; $(d \cdot n m)$, diameter in nanometers.

spectra of the as-prepared MF, the intermediate MF-NHS, and the MF-anti-CEA samples, respectively. Notice that in Figure 3(D) the SERS spectrum of the anti-CEA shell is also included for comparison, revealing characteristic Raman bands while not binding onto the MNPs.

In Figure 3(A), in the $1300-1650 \mathrm{~cm}^{-1}$ region there are bands related to the carboxylate, whereas in the $800-1300 \mathrm{~cm}^{-1}$ region Raman modes of $(\mathrm{C}-\mathrm{S})$ and $(\mathrm{C}-\mathrm{C})$ bonds of the skeletal chain of DMSA are observed. Additionally, the SERS spectrum of the MF sample reveals a new band around $500 \mathrm{~cm}^{-1}(\mathrm{~S}-\mathrm{S})$.

The MF-NHS SERS spectrum included in Figure 3(B) presents the same features as the MF sample SERS spectrum included in Figure 3(A). However, a more detailed analysis of the SERS spectrum shown in Figure 3(B) reveals that the shoulder at $1625 \mathrm{~cm}^{-1}$ and weak features peaking at $1180 \mathrm{~cm}^{-1}$ and $751 \mathrm{~cm}^{-1}$ are respectively associated with the vibrations of $\mathrm{C}=\mathrm{O}, \mathrm{S}=\mathrm{O}$, and $\mathrm{N}-\mathrm{O}$ bonds of NHS. Raman shifts observed for vibrational modes of the MF-NHS carboxylate groups compared to the MF sample were slight.

In the MF-anti-CEA SERS spectrum a Raman peak at $1655 \mathrm{~cm}^{-1}$, related to the $\mathrm{C}=\mathrm{O}$ stretching of a secondary amide, is observed, as shown in Figure 3(C). Note that the $1655 \mathrm{~cm}^{-1}$ feature peak is absent in the free anti-CEA spectrum (Figure 3(D)).

It is important to note that all peaks observed in the free anti-CEA SERS spectrum were also observed in the MF-anti-CEA SERS spectrum (modes assigned with the amide groups of the protein structure, amino acid and terminal amines and carboxylic). Bands associated with the DMSA molecule are also identified in the SERS spectrum of the MF-anti-CEA sample included in Figure 3(C). In addition, the vibrational Raman energies associated with the anti-CEA conjugated onto MNPs show only slight changes when compared to the vibrational modes of free anti-CEA.

\section{In vitro cell binding and specificity}

Figure 4A shows CEA expression levels of the two human colorectal carcinoma cell lines in this study. LS174T cells have a high level of CEA expression, whereas no CEA was detected by ELISA in HCT116 cells. In order to evaluate cellbinding efficacy of the suspended nanoparticles within the MF-anti-CEA sample, ELISA was performed with LS174T 


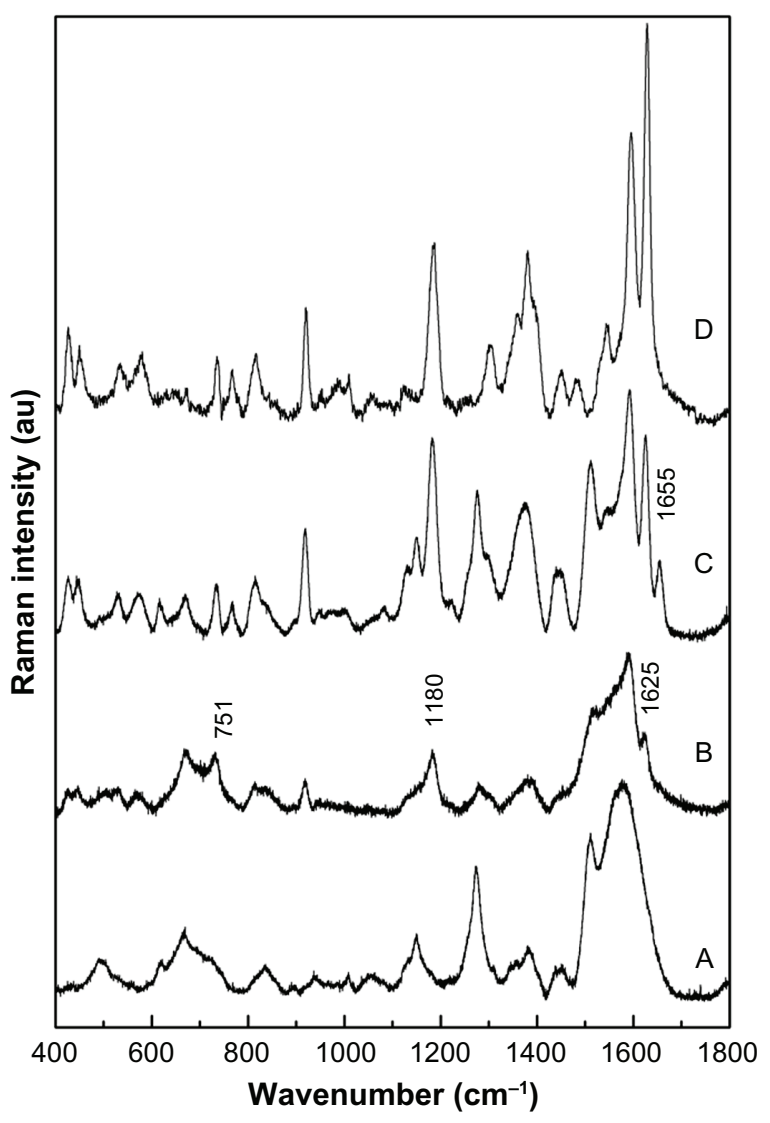

Figure 3 SERS. Raman spectra recorded for (A) MF, (B) MF-NHS, and (C) MF-antiCEA, and (D) free anti-CEA samples.

Abbreviations: SERS, surface enhanced Raman spectroscopy; MF, magnetic fluid; CEA, carcinoembryonic antigen.

cells and MF-anti-CEA as the primary antibody (Figure 4B). Data show cell binding by MF-anti-CEA and also by supernatants 1 and 2, but not supernatant 3 .

ELISA was also performed with both LS174T and HCT116 cells (Figure 4C) to verify MF-anti-CEA specificity for CEA. The signal of LS174T cells assessed by MF-antiCEA was statistically equal $(P=0.63)$ to the signal of antiCEA free antibody and statistically higher $(P=0.00)$ than the signal observed for HCT116 cells.

\section{Perls Prussian blue iron staining}

Perls Prussian blue staining was another test performed to confirm MF-anti-CEA specificity (Figure 5). Although the same iron concentration was employed in all cell cultures, there was an increase in the amount of bluestained iron in cells cultivated with the MF-anti-CEA sample when compared to those cultivated with the MF sample (Figure 5B, C, E and F). We also observed that the amount of blue-stained iron was higher for LS174T than for HCT116 cells (Figure 5C and F).

\section{Transmission electron microscopy}

TEM was performed to evaluate if the anti-CEA bonded in MNPs would improve MNP uptake by CEA-expressing cells. Both LS174T and HCT116 cells were cultured with either MF or MF-anti-CEA and analyzed about MNPs' localization inside or outside the cells.

MNPs of both MF and MF-anti-CEA samples were observed in the cytoplasm of both HCT116 and LS174T cells (Figure 6). However, an apparently increased number of LS174T cells with internalized MF-anti-CEA MNPs were observed while in comparison to the number of LS174T cells which internalized MF MNPs. Additionally, the presence of anti-CEA seems not to cause this increase in HCT116 cells.

\section{Discussion}

It has been reported that the early detection of cancer improves disease prognosis and cure and therefore sensitive methodologies with minimal invasion that are able to detect cancer cells are being developed. ${ }^{25-27}$ In this context, MNPs are very promising. Due to their superparamagnetic core, MNPs can be efficiently detected by MRI with high sensitivity and tissue resolution. ${ }^{28}$ Furthermore, MNPs are more biocompatible and present longer circulation time than the toxic gadolinium complex-based contrast agent used clinically. ${ }^{29}$ Besides these interesting characteristics, MNPs have been also studied for cancer therapy application. Due to their iron core, they are suitable for magnetic hyperthermia. When submitted to an $\mathrm{A} / \mathrm{C}$ magnetic field, MNPs release thermal energy, providing heating and leading to cell death and subsequently to a decrease in tumor size. ${ }^{7,8}$ Besides application in the magnetohyperthermia process, MNPs may also be designed for multiple potential therapeutic approaches such as chemotherapeutic delivery carriers, and photodynamic therapy. $9,10,30$

In the present study we developed a biocompatible nanosized material, labeled MF-anti-CEA, with potential for both diagnosis and treatment of CEA-expressing cancer cells, such as CRC cells. MF-anti-CEA biocompatibility was confirmed by MTT assay using HCT116 and LS174T cells cultivated with MF, the MF-anti-CEA precursor. Both cell lines were chosen to evaluate the specificity of the asprepared MF-anti-CEA device.

MTT data show that, in spite of an initial decrease in HCT116 cell viability, cells were able to recover to normal levels whereas the time for cell retrieval was found to be dependent upon iron concentration. For cultures with $60 \mathrm{ng} / \mu \mathrm{L}$ MF sample, the cell viability was already 
A

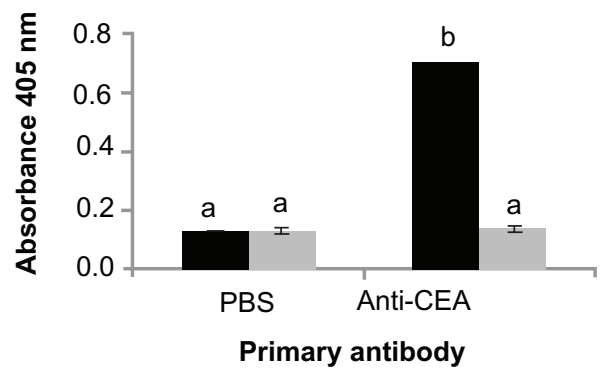

в
C

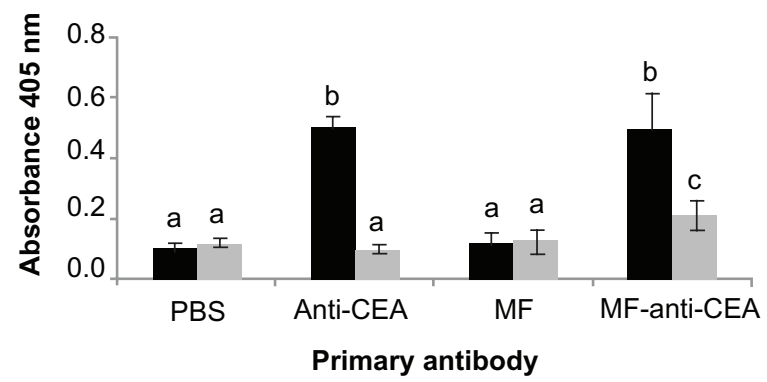

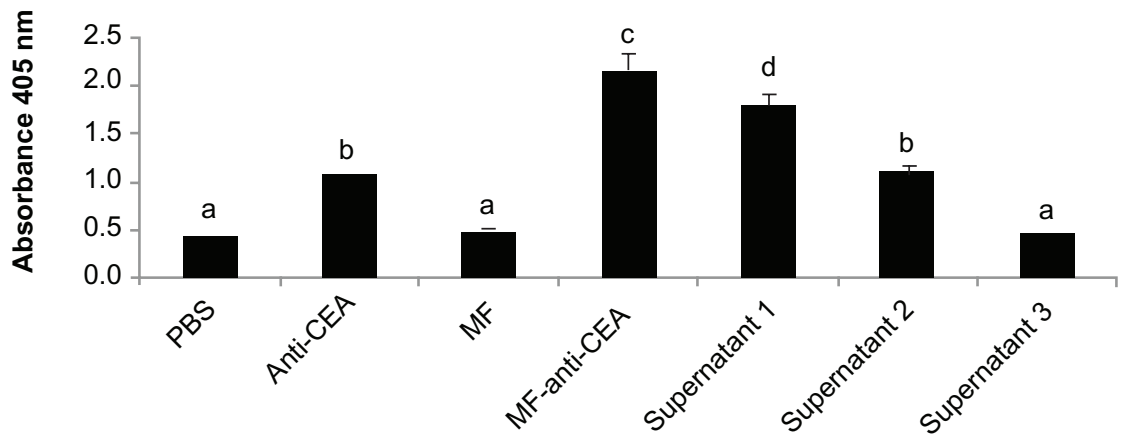

Primary antibody

Figure 4 In vitro cell binding and specificity of MF-anti-CEA by ELISA. (A) Detection of CEA expressed in human colorectal cancer cells. LSI74T and HCTI I6 cells were assessed by ELISA with anti-CEA at two different concentrations as primary antibody; (B) LSI74T cells' binding efficacy of MF-anti-CEA. ELISA was performed with either MF-anti-CEA or supernatants from antibody conjugation process as primary antibody; (C) MF-anti-CEA specificity for CEA was assessed in LSI74T and HCTII6 cells by ELISA with MF-anti-CEA as primary antibody. In figures (B and C) PBS and MF were utilized as negative controls and free anti-CEA antibody as positive control.

Note: Different letters mean statistical difference $(P<0.05)$.

Abbreviations: MF, magnetic fluid; CEA, carcinoembryonic antigen; ELISA, enzyme-linked immunosorbent assay; PBS, phosphate buffered saline.

comparable to the negative control in the time window of 12 hours, whereas at $80 \mathrm{ng} / \mu \mathrm{L} 48$ hours were needed to achieve the same result. It is reasonable to assume that cells were able to recover because they were not irreversibly damaged. Indeed, for human lung epithelial cells cultivated for 25 hours with maghemite and carbon black nanoparticles, Berg et $\mathrm{al}^{31}$ observed a decrease in cell viability assessed by MTT while no cell death was detected by other tests.

In LS174T cells, no toxicity was observed for 24 hours. Similar results were obtained by Chen et $\mathrm{l}^{32}$ for HeLa cells cultivated for 24 hours with graphene oxide-loaded magnetite nanoparticles, which were considered as a biocompatible sample because they caused no decrease in HeLa cells' viability, even at iron concentrations up to $80 \mathrm{ng} / \mu \mathrm{L}$, the same maximum concentration we used in our study.

Ankamwar et $\mathrm{al}^{33}$ suggested that magnetite nanoparticles presenting no reduction in cell viability (for different cell lines) at a concentration of $10 \mathrm{ng} / \mu \mathrm{L}$ may be considered biocompatible, even though at $100 \mathrm{ng} / \mu \mathrm{L}$ they may induce a decrease in cell viability of some cell lines. In this way, despite the decrease in LS174T cell viability after 48 hours culture with the MF sample at iron concentrations ranging from 30 to $80 \mathrm{ng} / \mu \mathrm{L}$, the sample may still be considered biocompatible.

Furthermore, comparing HCT116 and LS174T cells' viability after culture with $\mathrm{H}_{2} \mathrm{O}_{2}$ (positive control), we
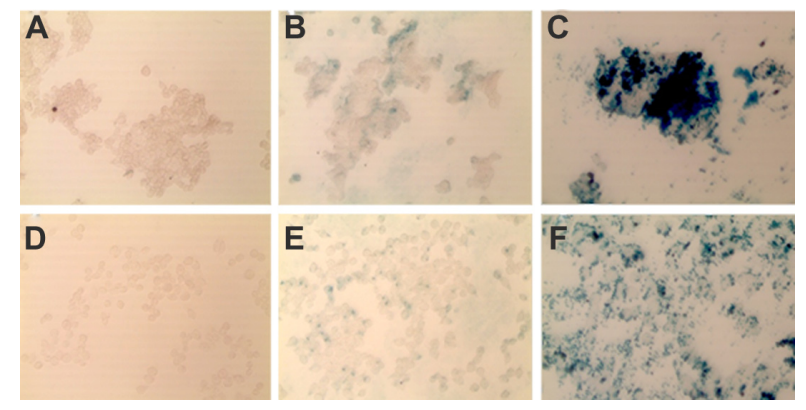

Figure 5 In vitro specificity of MF-anti-CEA by Prussian blue iron staining. LSI74T (A-C) and HCTII6 (D-F) cells were cultivated for 5 hours with MF (B and E), and MF-anti-CEA (C and $\mathbf{F})$ at same iron concentration $(60 \mathrm{ng} / \mu \mathrm{L})$. Untreated cells (A and $\mathbf{D})$ were negative control.

Abbreviations: MF, magnetic fluid; CEA, carcinoembryonic antigen. 


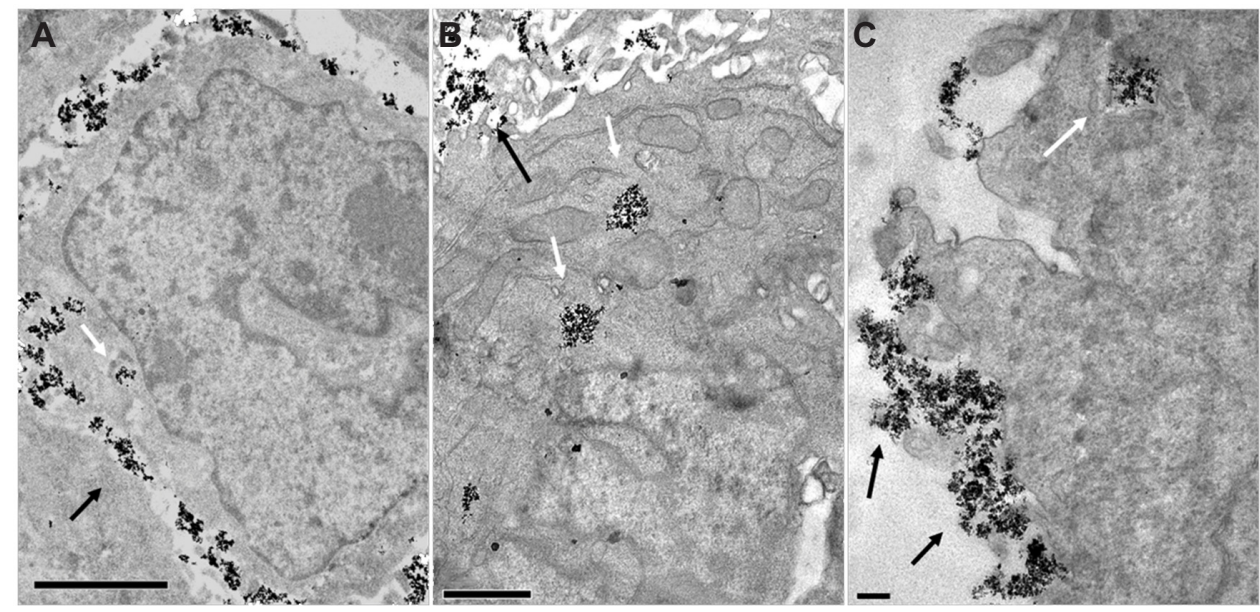

Figure 6 MNP uptake into human colorectal cancer cells. Electron micrographs of LSI74T cells incubated with MF MNP (A) or MF-anti-CEA MNP (B) and HCTII6 cell incubated with MF-anti-CEA MNP (C).

Notes: Arrows point to MNP aggregates. Bars $=2$ um (A) I $\mu \mathrm{m}$ (B) $0.5 \mu \mathrm{m}$ (C).

Abbreviations: MNP, maghemite nanoparticle; MF, magnetic fluid; CEA, carcinoembryonic antigen.

observed that the former is more susceptible to oxygen peroxide effects. After being cultivated for 5 hours with $0.1 \mathrm{mM} \mathrm{H}_{2} \mathrm{O}_{2}, \mathrm{HCT} 116$ cells presented a significant decrease in cell viability, whereas for LS174T cells this decrease was observed only after 12 hours. As $\mathrm{H}_{2} \mathrm{O}_{2}$ iron-based nanoparticles can generate reactive oxygen species (ROS), ${ }^{34}$ it is reasonable to assume that the transient decrease in HCT116 cell viability induced by the MF sample was more likely caused by ROS. If the effects of $\mathrm{H}_{2} \mathrm{O}_{2}$ on the LS174T cell line are delayed when compared to the HCT116 cell line, we can hypothesize that LS174T cells would be able to recover to normal cell viability levels if MTT assays are performed after longer periods of time.

Viability results obtained by in vitro MTT tests show that the MF sample containing DMSA-coated MNPs used in this study is biocompatible. Likewise, data in the literature show that magnetic fluid samples based on DMSA-coated magnetite nanoparticles investigated in animals are also biocompatible. ${ }^{35}$ Therefore, we considered that the employed MF sample could be used as an adequate MF-anti-CEA precursor.

After anti-CEA conjugation onto MNPs, MF-anti-CEA was characterized by TEM and dynamic light scattering. The conjugation process did not alter MNPs' morphology but did increase the hydrodynamic size. The increase in hydrodynamic size is frequently observed after antibody conjugation onto nanosized particles. ${ }^{36,37}$ However, the hydrodynamic diameter increase is usually smaller (ranging from 15 to $60 \mathrm{~nm}$ ) than that observed in this study. This finding is probably related not only to anti-CEA conjugation but also to MNP aggregation. Actually, the literature reports that both large particles and particle aggregates increase light scattering. ${ }^{38}$ The small peak around $100 \mathrm{~nm}$ observed in MF-anti-CEA suggests that some MNPs were not bound to anti-CEA or did not aggregate after conjugation, whereas the small feature peaking at about $5 \mu \mathrm{m}$ indicates MNPs sedimentation in the MF-anti-CEA sample, especially because it was apparent only in the third measurement. Dynamic light scattering also provided the zeta potential of MF-anti-CEA and its precursor MF. The negative values obtained for $\mathrm{MF}$ and MF-anti-CEA samples, ranging from $-47.5 \mathrm{mV}$ to $-38 \mathrm{mV}$, are in accordance with those reported in the literature for antibody-conjugated nanoparticles and suggest stability. ${ }^{39}$

In order to assess the efficiency of anti-CEA binding onto nanoparticles, SERS was successfully used. This tool allowed tracking the surface decoration of the nanosized maghemite particles from the very first precoating up to the attachment of the anti-CEA moiety. In the MF sample spectrum, the bands related to carboxylate and the Raman modes of $(\mathrm{C}-\mathrm{S})$ and $(\mathrm{C}-\mathrm{C})$ bonds of the skeletal chain of DMSA indicate that DMSA is covalently bonded through the carboxylate terminal onto the MNPs surface. Furthermore, in the MF sample spectrum the Raman mode of $\mathrm{v}(\mathrm{S}-\mathrm{S})$ was also observed, which is characteristic of disulfide cross-linkages (S-S) among molecular units of neighboring DMSA attached onto the MNPs surface. Actually, the S-S cross-linkages are alleged to play a key role in the stabilization of the built in surface molecular layer. ${ }^{40}$ Data obtained by Raman also allow the observation of a NHS-linker effectively attached at the surface of the MNPs suspended within the MF sample, because the shoulder at $1625 \mathrm{~cm}^{-1}$ and weak features peaking 
at 1180 and $751 \mathrm{~cm}^{-1}$ are respectively associated with the vibrations of $\mathrm{C}=\mathrm{O}, \mathrm{S}=\mathrm{O}$, and $\mathrm{N}-\mathrm{O}$ bonds of NHS. Small Raman shifts observed for vibrational modes of the MF-NHS carboxylate groups compared to the MF sample suggest that NHS is not strongly bonded to the DMSA shell, as expected. In fact, NHS is an intermediate linker for a subsequent step, namely the reaction between DMSA carboxyl and anti-CEA amine groups. This reaction is evidenced by the onset of a Raman peak at $1655 \mathrm{~cm}^{-1}$ present in the MF-anti-CEA SERS spectrum, but absent in the free anti-CEA spectrum. According to Parker ${ }^{41}$ the Raman mode peaking at $\sim 1655 \mathrm{~cm}^{-1}$ is assigned to the $\mathrm{C}=\mathrm{O}$ stretching of a secondary amide. Thus, the presence of this peak is claimed to be due to the vibration of a carbonyl group formed after conjugation of the antiCEA to the DMSA linked onto the MNPs. Interestingly, modes assigned to the amide groups of the protein structure, amino acid and terminal amines and carboxylic observed in all peaks of free anti-CEA spectrum, are also present in the MF-anti-CEA spectrum, confirming anti-CEA conjugation. Furthermore, the slight changes in the vibrational Raman energies associated with the anti-CEA conjugated onto MNPs when compared to the vibrational modes of free anti-CEA demonstrate that the process of conjugation does not lead to a relevant denaturation, consequently suggesting that its biological functions are fully preserved. Indeed, as revealed in the discussion presented above, SERS was used as a key experimental tool to investigate the binding process of molecules onto MNPs as well as the signatures of the molecular surface decoration in the final product, in our case the MF-anti-CEA sample. According to Occhipinti et al, ${ }^{42}$ conservation of the antibody biological functionality after conjugation is poorly evidenced due to the lack of reliable methods for assessing information in regard to the structural/conformational features that indicate antibody functionality. In the present study, however, we found SERS was successfully employed to evaluate the anti-CEA binding onto MNPs. Besides being suitable for demonstrating the antibody conjugation and how the antibody is chemically bonded, SERS also provided information that suggests antiCEA functionality was preserved.

Anti-CEA functionality after the conjugation process was confirmed by ELISA and Prussian blue iron staining performed with both LS174T and HCT116 cells. ELISA was performed to compare CEA expression between cell lines, and the results are in accordance with the literature. LS174T are high-level CEA-expressing cells, ${ }^{23}$ producing around $2 \mu \mathrm{g} / 10^{6}$ cells $/ 10$ days ${ }^{43}$ whereas HCT 116 cells express low levels of CEA estimated to be about $1-2 \mathrm{ng} / 10^{6}$ cells $/ 3$ days, ${ }^{24}$ which was not detected by ELISA. Due to their different CEA expression levels these two cell lines were chosen to assess cell binding and specificity of the as-prepared MFanti-CEA sample.

MF-anti-CEA was able to target LS174T cells, confirming Raman evidence of anti-CEA functionality. Since MF-anti-CEA targeting of LS174T cells was statistically higher than of HCT116 cells, as observed by ELISA and confirmed by Perls Prussian iron staining, we can state that the as-developed MF-anti-CEA is highly specific for CEAexpressing cells. It is also important to emphasize that there was no binding when supernatant 3 was used as the primary antibody. Since supernatant 3 represents the last washing of MNPs in the anti-CEA conjugation process, this important result shows that unconjugated antibodies were successfully removed from MF-anti-CEA.

After verifying that the suspended nanoparticles within the MF-anti-CEA sample are able to specifically bind to their target, TEM was performed to evaluate the cellular uptake of MNPs. Indeed the binding of MF-anti-CEA to CEA expressed in cell membranes improved MNP uptake by target cells. Apart from providing specific binding of MNPs to target cells, which is very suitable for specific diagnosis and magnetohyperthermia applications, the anti-CEA conjugated to MNPs facilitated MNP uptake by target cells. These data strongly suggest that MF-anti-CEA is a very promising material device for carrying drugs, since the efficiency of a drug-delivery system based on MNPs may depend on the specific accumulation of MNPs inside cancer cells. ${ }^{22}$

Taken together, the results obtained in this study indicate that the as-developed MF-anti-CEA device has enormous therapeutic potential as MF-anti-CEA and can be further engineered to act as a drug-delivery system or alternatively to be used in magnetohyperthermia, while responding to an A/C magnetic field. Moreover, MF-anti-CEA can also be tailored as a contrast agent in magnetic resonance for both diagnosis and imaging guided therapy.

\section{Conclusion}

In conclusion, this study reports on the preparation, characterization, and biological test of a potential theragnostics material device (MF-anti-CEA) engineered to specifically target CEA-expressing cancer cells. Anti-CEA antibody was successfully conjugated to DMSA-coated nanosized maghemite particles. The as-prepared MF-anti-CEA device was analyzed by TEM, dynamic light scattering, and electrophoretic mobility measurements, revealing desirable characteristics. SERS indicated that anti-CEA is successfully 
bonded onto DMSA-coated nanosized maghemite particles, leading to a specific targeting capability to CEA expressing CRC cells, as showed by ELISA and Prussian blue iron staining. Furthermore, the presence of the antibody anti-CEA seems to facilitate the preferential uptake of the MF-anti-CEA device by CEA expressing LS174T cells. Data suggests MF-anti-CEA is a potential theragnostics tool for CEA-expressing tumors, micrometastasis, and cancer circulating cells.

\section{Acknowledgments/disclosures}

The authors report no conflicts of interest in this work. We thank the Brazilian agencies CNPq, REDE CON-NANO/ CAPES-, INCT-Nanobiotecnologia (MCT/CNPq), CNANO/ $\mathrm{IB} / \mathrm{UnB}, \mathrm{DPP} / \mathrm{UnB}$, and FAP-DF for financial support. We are grateful to Dr Izabel Cristina da Silva for assistance with statistical analysis. We thank Dr Alexsandro Galdino and Msc José Luiz Jivago de Paula for assistance with artwork.

\section{References}

1. Siegel R, Ward E, Brawley O, Jemal A. Cancer statistics, 2011: the impact of eliminating socioeconomic and racial disparities on premature cancer deaths. CA Cancer J Clin. 2011;61(4):212-236.

2. Bünger S, Haug U, Kelly FM, et al. Toward standardized highthroughput serum diagnostics: multiplex-protein array identifies IL-8 and VEGF as serum markers for colon cancer. J Biomol Screen. 2011; 16(9):1018-1026.

3. Li M, Kim HS, Tian L, Yu MK, Jon S, Moon WK. Comparison of two ultrasmall superparamagnetic iron oxides on cytotoxicity and MR imaging of tumors. Theranostics. 2012;2(1):76-85.

4. Lim SW, Kim HW, Jun HY, et al. TCL-SPION-enhanced MRI for the detection of lymph node metastasis in murine experimental model. Acad Radiol. 2011;18(4):504-511.

5. Cheng L, Yang K, Li Y, et al. Multifunctional nanoparticles for upconversion luminescence/MR multimodal imaging and magnetically targeted photothermal therapy. Biomaterials. 2012;33(7):2215-2222.

6. Zhang L, Zhong X, Wang L, et al. $\mathrm{T}_{1}$-weighted ultrashort echo time method for positive contrast imaging of magnetic nanoparticles and cancer cells bound with the targeted nanoparticles. J Magn Reson Imaging. 2011;33(1):194-202.

7. Portilho F, Estevanato L, Miranda-Vilela A, et al. Investigation of a magnetohyperthermia system efficacy. J Appl Phys. 2011;109(7): $07 \mathrm{~B} 307$.

8. Balivada S, Rachakatla $\mathrm{R}$, Wang $\mathrm{H}$, et al. A/C magnetic hyperthermia of melanoma mediated by iron (0)/iron oxide core/shell magnetic nanoparticles: a mouse study. BMC Cancer. 2010;10:119.

9. Carneiro ML, Nunes ES, Peixoto RC, et al. Free Rhodium (II) citrate and rhodium (II) citrate magnetic carriers as potential strategies for breast cancer therapy. J Nanobiotechnology. 2011;9:11.

10. Primo FL, Rodrigues MM, Simioni AR, Lacava ZG, Morais PC, Tedesco AC. Photosensitizer-loaded magnetic nanoemulsion for use in synergic photodynamic and magnetohyperthermia therapies of neoplastic cells. J Nanosci Nanotechnol. 2008;8(11):5873-5877.

11. Taylor RM, Huber DL, Monson TC, Ali AM, Bisoffi M, Sillerud LO. Multifunctional iron platinum stealth immunomicelles: targeted detection of human prostate cancer cells using both fluorescence and magnetic resonance imaging. J Nanopart Res. 2011;13(10):4717-4729.

12. Quan G, Du X, Huo T, et al. Targeted molecular imaging of antigen OC183B2 in ovarian cancers using MR molecular probes. Acad Radiol. 2010;17(12):1468-1476.
13. Galanzha EI, Shashkov EV, Kelly T, Kim JW, Yang L, Zharov VP. In vivo magnetic enrichment and multiplex photoacoustic detection of circulating tumour cells. Nat Nanotechnol. 2009;4(12):855-860.

14. Shimada R, Iinuma H, Akahane T, Horiuchi A, Watanabe T. Prognostic significance of CTCs and CSCs of tumor drainage vein blood in Dukes' stage B and C colorectal cancer patients. Oncol Rep. 2012;27(4): 947-953.

15. Zhao YP, Ruan CP, Wang H, et al. Identification and assessment of new biomarkers for colorectal cancer with serum N-glycan profiling. Cancer. 2012;118(3):639-650.

16. Li M, Li JY, Zhao AL, et al. Survival stratification panel of colorectal carcinoma with combined expression of carcinoembryonic antigen, matrix metalloproteinases-2, and p27 kip1. Dis Colon Rectum. 2007; 50(11):1887-1898.

17. Artiko V, Petrović M, Sobić-Saranović D, et al. Radioimmunoscintigraphy of colorectal carcinomas with 99 mTc-labelled antibodies. Hepatogastroenterology. 2011;58(106):347-351.

18. Aarts F, Boerman OC, Sharkey RM, et al. Pretargeted radioimmunoscintigraphy in patients with primary colorectal cancer using a bispecific anticarcinoembryonic antigen CEA X anti-di-diethylenetriaminepentaacetic acid F (ab') 2 antibody. Cancer. 2010;116(Suppl 4):1111-1117.

19. Frampas E, Maurel C, Remaud-Le Saëc P, et al. Pretargeted radioimmunotherapy of colorectal cancer metastases: models and pharmacokinetics predict influence of the physical and radiochemical properties of the radionuclide. Eur J Nucl Med Mol Imaging. 2011; 38(12):2153-2164.

20. Homayounfar K, Liersch T, Niessner M, et al. Multimodal treatment options for bilobar colorectal liver metastases. Langenbecks Arch Surg. 2010;395(6):633-641.

21. Valois CR, Braz JM, Nunes ES, et al. The effect of DMSA-functionalized magnetic nanoparticles on transendothelial migration of monocytes in the murine lung via a beta2 integrin-dependent pathway. Biomaterials. 2010;31(2):366-374.

22. Acharya S, Dilnawaz F, Sahoo SK. Targeted epidermal growth factor receptor nanoparticle bioconjugates for breast cancer therapy. Biomaterials. 2009;30(29):5737-5750.

23. Fahlgren A, Baranov V, Frängsmyr L, Zoubir F, Hammarström ML, Hammarström S. Interferon-gamma tempers the expression of carcinoembryonic antigen family molecules in human colon cells: a possible role in innate mucosal defence. Scand J Immunol. 2003;58(6): 628-641.

24. Wang H, Rajagopal S, Reynolds S, Cederberg H, Chakrabarty S. Differentiation-promoting effect of 1-O (2 methoxy) hexadecyl glycerol in human colon cancer cells. J Cell Physiol. 1999;178(2):173-178.

25. Kendall C, Day J, Hutchings J, et al. Evaluation of Raman probe for oesophageal cancer diagnostics. Analyst. 2010;135(12):3038-3041.

26. Wajed SA. Personalized treatment-the promise of molecular genetics diagnostics. J Gastrointest Surg. 2010;14 Suppl 1:S2-S5.

27. Bharali DJ, Mousa SA. Emerging nanomedicines for early cancer detection and improved treatment: current perspective and future promise. Pharmacol Ther. 2010;128(2):324-335.

28. Yigit MV, Moore A, Medarova Z. Magnetic nanoparticles for cancer diagnosis and therapy. Pharm Res. 2012;29(5):1180-1188.

29. Kim BH, Lee N, Kim H, et al. Large-scale synthesis of uniform and extremely small-sized iron oxide nanoparticles for high-resolution T1 magnetic resonance imaging contrast agents. JAm Chem Soc. 2011; 133(32):12624-12631.

30. Estevanato L, Cintra D, Baldini N, et al. Preliminary biocompatibility investigation of magnetic albumin nanosphere designed as a potential versatile drug delivery system. Int J Nanomedicine. 2011;6:1709-1717.

31. Berg JM, Ho S, Hwang W, et al. Internalization of carbon black and maghemite iron oxide nanoparticle mixtures leads to oxidant production. Chem Res Toxicol. 2010;23(12):1874-1882.

32. Chen W, Yi P, Zhang Y, Zhang L, Deng Z, Zhang Z. Composites of aminodextran-coated $\mathrm{Fe} 3 \mathrm{O} 4$ nanoparticles and graphene oxide for cellular magnetic resonance imaging. ACS Appl Mater Interfaces. 2011;3(10):4085-4091. 
33. Ankamwar B, Lai TC, Huang JH, et al. Biocompatibility of $\mathrm{Fe}(3) \mathrm{O}(4)$ nanoparticles evaluated by in vitro cytotoxicity assays using normal, glia and breast cancer cells. Nanotechnology. 2010;21(7):75102.

34. Foy SP, Labhasetwar V. Oh the irony: Iron as a cancer cause or cure? Biomaterials. 2011;32(35):9155-9158.

35. Monge-Fuentes V, Garcia MP, Tavares MC, et al. Biodistribution and biocompatibility of DMSA-stabilized maghemite magnetic nanoparticles in nonhuman primates (Cebus spp.). Nanomedicine (Lond). 2011;6(9):1529-1544.

36. Driskell JD, Jones CA, Tompkins SM, Tripp RA. One-step assay for detecting influenza virus using dynamic light scattering and gold nanoparticles. Analyst. 2011;136(15):3083-3090.

37. Ling Y, Wei K, Luo Y, Gao X, Zhong S. Dual docetaxel/superparamagnetic iron oxide loaded nanoparticles for both targeting magnetic resonance imaging and cancer therapy. Biomaterials. 2011;32(29): $7139-7150$.

38. Jans H, Liu X, Austin L, Maes G, Huo Q. Dynamic light scattering as a powerful tool for gold nanoparticle bioconjugation and biomolecular binding studies. Anal Chem. 2009;81(22):9425-9432.
39. Satishkumar R, Vertegel AA. Antibody-directed targeting of lysostaphin adsorbed onto polylactide nanoparticles increases its antimicrobial activity against $S$. aureus in vitro. Nanotechnology. 2011;22(50):505103.

40. Soler MA, Lima EC, Nunes ES, et al. Spectroscopic study of maghemite nanoparticles surface-grafted with DMSA. J Phys Chem A. 2011; 115(6):1003-1008.

41. Parker FS. Applications of Infrared, Raman, and Resonance Raman Spectroscopy in Biochemistry. 1st ed. New York: Springer; 1983.

42. Occhipinti E, Verderio P, Natalello A, et al. Investigating the structural biofunctionality of antibodies conjugated to magnetic nanoparticles. Nanoscale. 2011;3(2):387-390.

43. ATCC. Cell lines and hybridomas [homepage on the Internet]. Available from: http://www.atcc.org/ATCCAdvancedCatalogSearch/Product Details $/$ tabid $/ 452 /$ Default.aspx ATCCNum=CL-188\&Template $=$ cellBiology. Accessed March 5, 2012.
International Journal of Nanomedicine

\section{Publish your work in this journal}

The International Journal of Nanomedicine is an international, peerreviewed journal focusing on the application of nanotechnology in diagnostics, therapeutics, and drug delivery systems throughout the biomedical field. This journal is indexed on PubMed Central, MedLine, CAS, SciSearch $\AA$, Current Contents ${ }^{\circledR} /$ Clinical Medicine,

\section{Dovepress}

Journal Citation Reports/Science Edition, EMBase, Scopus and the Elsevier Bibliographic databases. The manuscript management system is completely online and includes a very quick and fair peer-review system, which is all easy to use. Visit http://www.dovepress.com/ testimonials.php to read real quotes from published authors. 